\title{
Bioconversion of $\gamma$-aminobutyric acid and isoflavone contents during the fermentation of high-protein soy powder yogurt with Lactobacillus brevis
}

\author{
Chung Eun Hwang ${ }^{1} \cdot$ Md. Azizul Haque ${ }^{2} \cdot J_{i n}$ Hwan Lee $^{3}$ • \\ Yeong Hun Song ${ }^{4} \cdot$ Hee Yul Lee ${ }^{1}$ Su Cheol Kim ${ }^{1}$. \\ Kye Man Cho' ${ }^{1}$
}

Received: 17 January 2018/ Accepted: 27 March 2018/Published online: 30 May 2018

(C) The Korean Society for Applied Biological Chemistry 2018

\begin{abstract}
This study evaluated the changes in $\gamma$-aminobutyric acid (GABA) and isoflavone aglycone contents from soy powder yogurt (SPY) due to sprouting of soybean $(1 \mathrm{~cm})$ and fermentation with Lactobacillus brevis. The levels of GABA and the aglycone form increased, and the glutamate decarboxylase and $\beta$-glucosidase activities increased; however, the isoflavone glycoside and malonylglycoside contents decreased after fermentation for $72 \mathrm{~h}$. In particular, after $60 \mathrm{~h}$, the SPY presented the highest GABA content $(120.38 \mathrm{mg} / 100 \mathrm{~mL})$. The highest daidzein $(179.93 \mu \mathrm{g} / \mathrm{g})$, glycitein $(44.10 \mu \mathrm{g} / \mathrm{g})$, and genistein $(126.24 \mu \mathrm{g} / \mathrm{g})$ contents were present after $72 \mathrm{~h}$ of fermentation. In addition, the 2,2diphenyl-1-picrylhydrazyl, 2,2-azinobis (3-ethylbenzothiazoline-6-sulfonic acid) diammonium salt, and hydroxyl radical scavenging activities increased from 69.65, 97.94, and $70.90 \%$ during this fermentation, respectively. This result suggests that SPY may be used for the preparation of high-protein soybean with high GABA and isoflavone aglycone contents, which can then be used as a natural ingredient of functional foods.
\end{abstract}

Kye Man Cho

kmcho@gntech.ac.kr

1 Department of Food Science, Gyeongnam National University of Science and Technology, Jinju 52725, Republic of Korea

2 Department of Biochemistry and Molecular Biology, Hajee Mohammad Danesh Science and Technology University, Dinajpur 5200, Bangladesh

3 Division of Research Development and Education, National Institute of Chemical Safety, Ministry of Environment, Daejeon 34111, Republic of Korea

4 Division of Applied Life Science (BK21 Plus), IALS, Gyeongsang National University, Jinju 52828, Republic of Korea
Keywords Antioxidant activity · Fermentation - Gammaaminobutyric acid · Glutamic acid · Isoflavone .

Lactobacillus brevis $\cdot$ Soy powder yogurt

\section{Introduction}

As a nutritious plant food material, soybean (Glycine max L.) is widely used in the Asia area. Soybean contains approximately $40 \%$ protein, $20 \%$ oil, and $30 \%$ carbohydrate. The amino acids of soybean not only have a high nutritional value, but also provide several human health benefits $[1,2]$. Isoflavones are present in four chemicals, namely glycosides (25\%), malonylglycosides (70-80\%), acetylglycosides $(5 \%)$, and aglycones (2\%), in raw soybeans [3]. The chemical structures of the isoflavones and metabolites influence the extent of absorption of aglycone derivatives, which are more readily absorbed and bioavailable than highly polar conjugated glycoside derivatives [4]. In particular, soybean has been germinated for human consumption because germination can decrease the content of anti-nutritional factors while increasing the amount of nutrients and phytochemicals such as vitamin $\mathrm{E}$ and isoflavone aglycone derivatives [5, 6]. Additionally, Saedanbaek of the soybean cultivar contains approximately 48\% protein, including 25-30\% glutamic acid (GA) [3].

The $\gamma$-aminobutyric acid (GABA) is a four-carbon nonprotein amino acid that is produced primarily by L-glutamate decarboxylase and pyridoxal 5'-phosphate to succinate semialdehyde using enzymes with GABA transaminase activity [7, 8]. GABA has beneficiary functions in animal physiology, such as neurotransmission, hypertension, and decreasing blood pressure secretion, making GABA attractive as an active material in functional 
foods [9]. Although GABA is often widely found in many plants and microorganisms, its contents are very low [7]. However, it was previously reported that GABA can be increased by soaking, germination of the soybean $[6,10]$. In particular, several microorganisms generally recognized as safe including lactic acid bacteria (LAB) such as Lactobacillus brevis [11-15], Lactobacillus paracasei [16], and Enterococcus raffinosus [17] have been widely studied and applied in GABA production over the last few years. Interestingly, GA is used to produce GABA, which is contained in most soybeans. Therefore, GABA production via fermentation and germination is believed to be convenient and efficient and has been applied in food technology. The health effects of soybean-based foods are due to the numerous functional ingredients in soybean, especially isoflavones [4].

The main purpose of the present research was to investigate the changes in the functional factors, including GABA and isoflavone aglycone derivatives, during sprouting of high-protein soy powder yogurt (SPY) upon fermentation with L. brevis. In addition, changes in the $\beta$ glycosidase and glutamate decarboxylase activities and the antioxidant activity of soy powder milk (SPM) during fermentation were evaluated.

\section{Materials and methods}

\section{Soybean, medium, and chemicals}

The high-protein soybean (HPS) cultivar, "Saedanbaek," was provided by the National Institute of Crop Science (Miryang, Korea) in 2014. Lactobacillus brevis KCTC 3320 was collected from a Korean culture-type collection. Three glycosides and aglycones, including daidzin, glycitin, genistin, daidzein, glycitein, and genistein, were purchased from the Sigma-Aldrich Chemical Co. (St. Louis, MO, USA). Three malonyl- and acetylglycosides (malonyldaidzin, malonylglycitin, malonylgenistin, acetyldaidzin, acetylglycitin, and acetylgenistin) were obtained from LC Laboratories (Woburn, MA, USA). GA, GABA, bromocresol green, pyridoxal-5-phosphate (PLP), glacial acetic acid, $2 \mathrm{~N}$ Folin-Ciocalteu phenol reagent, 2,2-diphenyl-1-picrylhydrazyl (DPPH), 2,2-azinobis (3ethylbenzothiazoline-6-sulfonic acid) diammonium salt (ABTS), potassium persulfate, $p$-nitrophenol- $\beta$-D-glucopyranoside ( $p$-NPG), $p$-nitrophenol- $\beta$-butyric acid ( $p$ NPB), and $p$-nitrophenol were obtained from the SigmaAldrich Chemical Co. HPLC-grade $\mathrm{H}_{2} \mathrm{O}$, methanol, and acetonitrile were purchased from Fisher Scientific (Fairlawn, NJ, USA). All other reagents were of analytical grade.

\section{Preparation of HPS sprouts}

The sprouted HPS was following partially modified methods of Huang et al. [1]. Briefly, whole HPSs were washed and soaked in water at room temperature for $12 \mathrm{~h}$. After soaking, the soybeans were put into a semi-automatic sprouting machine (model HANCELL, Gwangmyeong, Korea). The HPSs were automatically watered every hour for $8 \mathrm{~h}$ and were sprouted for 5 days $(0,1,2$, and $4 \mathrm{~cm})$ in an incubator at $20{ }^{\circ} \mathrm{C}$. The sprouted HPS samples were steamed for $30 \mathrm{~min}$ at $121{ }^{\circ} \mathrm{C}$. The steamed HPSs were harvested and stored in a deep freezer at $-70{ }^{\circ} \mathrm{C}$ until further analysis.

\section{Preparation and the fermentation of soy powder yogurt}

The different processing conditions of HPSs, namely fresh, steamed and sprouting of steamed HPSs, were dried at 55 $\pm 2{ }^{\circ} \mathrm{C}$ for 3 days after and were crushed for the production of soy powder. The $10 \mathrm{~g}$ of soy powder was mixed with $100 \mathrm{~mL}$ of $2 \%$ sucrose solution in different containers. This mixture, namely soy powder milk (SPM, unfermented high-protein soybean sprouts), was then sterilized in an autoclave at $121{ }^{\circ} \mathrm{C}$ for $15 \mathrm{~min}$. After the seed culture contained approximately $8.0 \log \mathrm{cfu} / \mathrm{mL}$ with $L$. brevis, the SPM was fermented at $30 \pm 1{ }^{\circ} \mathrm{C}$ for $72 \mathrm{~h}$ (soy powder yogurt, SPY, fermented high-protein soybean sprouts), and sampling was carried out at $0,12,24,36,48,60$, and $72 \mathrm{~h}$. The SPM and SPY samples were stored at $-70^{\circ} \mathrm{C}$ until analysis.

\section{pH, titratable acidity (TA), and viable cell numbers}

The $\mathrm{pH}$ values of the SPM and SPY samples were measured using a $\mathrm{pH}$ meter (MP 200, London, UK), whereas the titratable acidity (TA) was determined by titration with $0.01 \mathrm{M} \mathrm{NaOH}$ and expressed as lactic acid (\%) according to the methods previously described by Hwang et al. [18]. To measure the viable cell numbers, $1 \mathrm{~mL}$ of each sample was dissolved in $9 \mathrm{~mL}$ of sterilized distilled water at room temperature and the diluted suspension was spread on MRS agar plates. The plate was incubated at $30{ }^{\circ} \mathrm{C}$ for $48 \mathrm{~h}$, after which colony counts were conducted.

\section{Glutamate decarboxylase assay}

The enzyme assays for the glutamate decarboxylase activity were spectrophotometrically analyzed according to the method of $\mathrm{Yu}$ et al. [19]. The standard reaction medium in each well consisted of $200 \mu \mathrm{L}$ of acetate buffer $(20 \mathrm{mM}$, $\mathrm{pH} 5.5)$ containing $50 \mu \mathrm{mol}$ of bromocresol green, $10 \mathrm{mM}$ of PLP, $10 \mu \mathrm{L}$ of $1 \%$ glutamic acid, and crude enzyme extract (2.5 unit). After reaction at $48{ }^{\circ} \mathrm{C}$ for $30 \mathrm{~min}$, the 
absorbance of the mixture was then determined at $620 \mathrm{~nm}$ (Spectronic 2D, Thermo Co., Petaluma, CL, USA).

\section{$\beta$-Glucosidase assay}

The enzyme assay for the $\beta$-glycosidase activity was spectrophotometrically analyzed according to the method of Cho et al. [20]. The extract $(250 \mu \mathrm{L})$ was added to $250 \mu \mathrm{L}$ of the substrate ( $5 \mathrm{mM}$ p-NPG or $5 \mathrm{mM} \mathrm{p}-\mathrm{NPB}$ ) in $50 \mathrm{mM}$ sodium phosphate buffer (pH 7.0). After $30 \mathrm{~min}$ of incubation at $37^{\circ} \mathrm{C}$, the enzymatic reaction was stopped by adding $500 \mathrm{~mL}$ of $0.2 \mathrm{M}$ glycine- $\mathrm{NaOH}(\mathrm{pH} 10.5)$ and the contents were immediately measured in a spectrophotometer (Spectronic 2D) at $405 \mathrm{~nm}$.

\section{Free amino acid (FAA) contents}

Free amino acids (FAAs) were analyzed according to the method described by Kim and Ji [11]. One milliliter of sample was added to $4 \mathrm{~mL}$ of distilled water, and then a heating block (HB-48P, DAIHAN Scientific, Seoul, Korea) was used to drive hydrolysis at $60{ }^{\circ} \mathrm{C}$ for $1 \mathrm{~h}$. After $1 \mathrm{~mL}$ of 5-sulfosalicylic acid (10\%) was added, the mixture was vortexed for $1 \mathrm{~min}$ and maintained at $4{ }^{\circ} \mathrm{C}$ for $2 \mathrm{~h}$. After centrifuging at $3000 \mathrm{rpm}$ for $3 \mathrm{~min}$, the supernatant was collected and syringe-filtered using a rotary vacuum evaporator at $60{ }^{\circ} \mathrm{C}$. The lithium buffer ( $\mathrm{pH} 2.2$ ) was dissolved by applying membrane filtration. The free amino acids content was determined using an amino acid analyzer (Hitachi L-8900, Tokyo, Japan).

\section{Production of extracts from SPM and SPY}

The SPM and SPY samples were freeze-dried into a powder $(1.0 \mathrm{~g})$ and extracted with $10 \mathrm{~mL}$ of $50 \%$ methanol $(\mathrm{MeOH})$ by shaking $(280 \mathrm{rpm})$ at $25^{\circ} \mathrm{C}$ for $12 \mathrm{~h}$ and filtered through Whatman No. 42 filter paper. The extract solution was dissolved in $10 \mathrm{~mL}$ of $50 \% \mathrm{MeOH}$ and filtered through a $0.45-\mu \mathrm{m}$ Minipore PVDF filter (Schleicher \& Schuell, GmbH, Dassel, Germany).

\section{Analysis of total phenolic contents}

The $0.5 \mathrm{~mL}$ of $50 \% \mathrm{MeOH}$ extract was mixed with $0.5 \mathrm{~mL}$ of a $25 \%$ sodium carbonate $\left(\mathrm{Na}_{2} \mathrm{CO}_{3}\right)$ solution and $0.25 \mathrm{~mL}$ of Folin-Ciocalteu reagent in a test tube and was kept at $30^{\circ} \mathrm{C}$ for $1 \mathrm{~h}$. The absorbance of the mixtures was determined at $750 \mathrm{~nm}$ (Spectronic 2D). A gallic acid equivalent standard curve was prepared according to the method of Lee et al. [3].

\section{Analysis of isoflavone contents}

The quantification of the isoflavone in the $50 \% \mathrm{MeOH}$ extracts was carried out by a high-performance liquid chromatography (HPLC, Agilent Co., Santa Clara, CL, USA) equipped with a diode array detector. The extracts were separated on a $100 \mathrm{RP} \mathrm{C}_{18}$ column $(4.6 \times 250 \mathrm{~mm}$, $5.0 \mu \mathrm{m}$, Merck, Germany) at $30^{\circ} \mathrm{C}$. The injection volume was $20 \mu \mathrm{L}$ for all extracts, and the flow rate was $1.0 \mathrm{~mL} /$ min. The following binary mobile phase consisting of (A) $0.2 \%$ acetic acid in water and (B) $0.2 \%$ acetic acid in acetonitrile was used for the separation of isoflavone: $0 \mathrm{~min}, 100 \% \mathrm{~A} ; 15 \mathrm{~min}, 90 \% \mathrm{~A} ; 25 \mathrm{~min}, 80 \% \mathrm{~A} ; 35 \mathrm{~min}$, $75 \% \mathrm{~A} ; 45 \mathrm{~min}, 65 \% \mathrm{~A} ; 50 \mathrm{~min}, 65 \%$. All isoflavone peaks were detected and monitored at $254 \mathrm{~nm}$ [2].

\section{DPPH radical scavenging activity}

The DPPH radical scavenging activity of the fermented $50 \% \mathrm{MeOH}$ extracts was performed according to the method described by Hwang et al. [18]. Specifically, DPPH solution $\left(1.5 \times 10^{-4} \mathrm{mM}, 0.8 \mathrm{~mL}\right)$ was mixed with the SPM and SPY extracts. After standing at room temperature for $30 \mathrm{~min}$, the absorbance of the mixture was determined at $525 \mathrm{~nm}$ using a spectrophotometer (Spectronic 2D).

\section{ABTS radical scavenging activity}

The ABTS radical scavenging activity was following the modified methods of Hwang et al. [18]. The ABTS stock solution diluted 50 times with SPY extract $(0.1 \mathrm{~mL})$ was added to $0.9 \mathrm{~mL}$ of $\mathrm{ABTS}^{\bullet+}$ solution. After being kept in the dark at room temperature for $3 \mathrm{~min}$, the absorbance was determined at $730 \mathrm{~nm}$ using spectrophotometry (Spectronic 2D).

\section{Hydroxyl radical scavenging activity}

The hydroxyl (.OH) radical scavenging capacity was performed using $50 \%$ methanol extracts, as recently described by Herraiz and Galisteo [16]. All of the reagents, such as $10 \mathrm{mM} \mathrm{FeSO} \cdot 7 \mathrm{H}_{2} \mathrm{O}$-EDTA, $10 \mathrm{mM}$ 2-deoxyribose, $2.8 \%$ trichloroacetic acid, and $1 \%$ thiobarbituric acid, were dissolved in $\mathrm{KH}_{2} \mathrm{PO}_{4}-\mathrm{KOH}$ buffer $(10 \mathrm{mM}$, $\mathrm{pH} 7.4)$, and the reaction was initiated upon the addition of $\mathrm{H}_{2} \mathrm{O}_{2}(10 \mathrm{mM})$. After incubation at $37{ }^{\circ} \mathrm{C}$ for $1 \mathrm{~h}$, the reaction was stopped by adding $0.7 \mathrm{~mL}$ of $2.8 \%$ trichloroacetic acid and $0.7 \mathrm{~mL}$ of $1 \%$ barbituric acid. The mixture was heated in a water bath at $100{ }^{\circ} \mathrm{C}$ for $10 \mathrm{~min}$ and then cooled in water at room temperature. The absorbance of the resulting solution was measured at $532 \mathrm{~nm}$ (Spectronic 2D). 


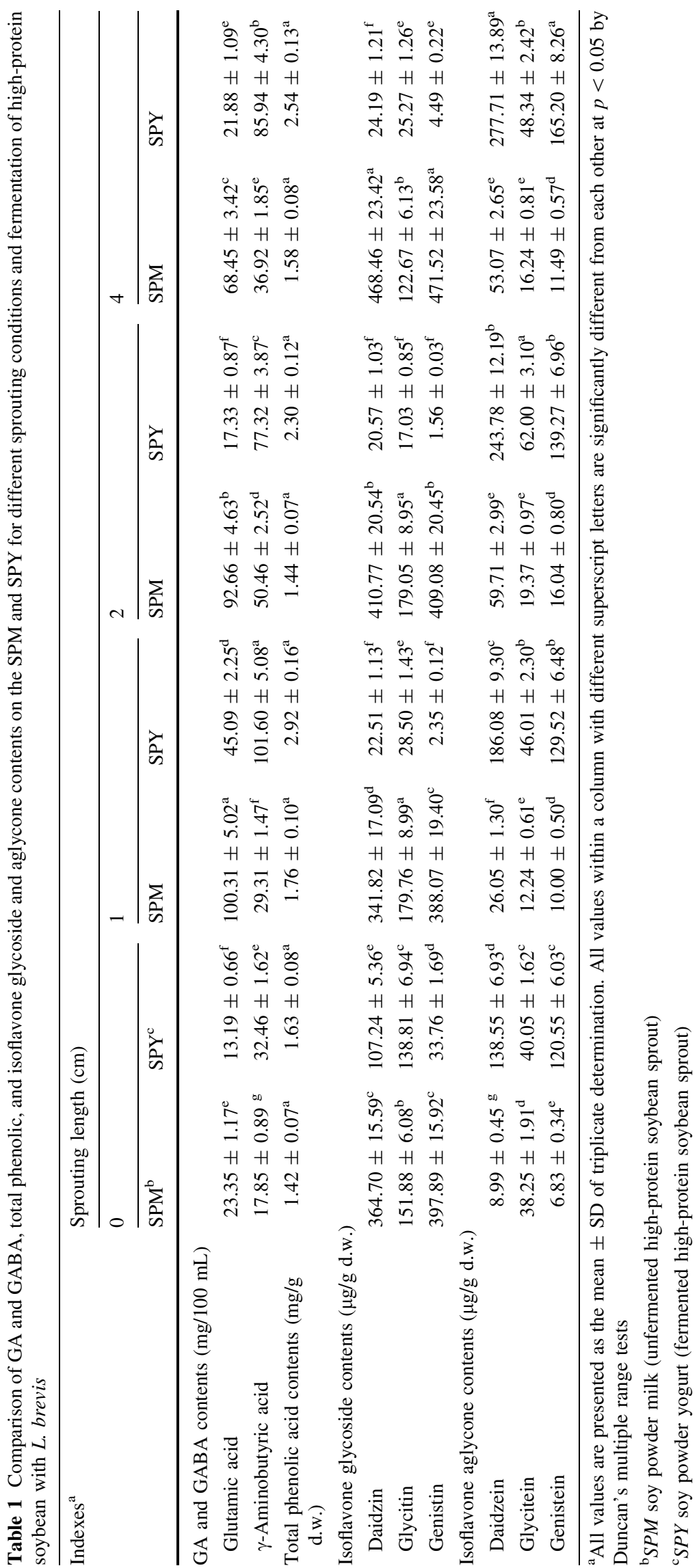




\section{Statistical analysis}

All experimental values are presented as the mean \pm SD of triplicate determination. Differences in the means of each value were confirmed by one-way ANOVA followed by the Tukey's multiple range tests at $p<0.05$ using the Statistical Analysis System.

\section{Results and discussion}

\section{Confirmation of optimum sprouting conditions}

A comparison of the GA, GABA, total phenolic, and isoflavone aglycone contents in the SPM and SPY samples is shown in Table 1. As shown, the GA contents decreased from 100.31 to $45.09 \mathrm{mg} / 100 \mathrm{~mL}$ and the corresponding GABA contents increased to a maximum of $101.60 \mathrm{mg} /$ $100 \mathrm{~mL}$ at $72 \mathrm{~h}$ upon the fermentation of one sprouting soybean (SPY-1 cm) (Table 1). In particular, the highest concentration of GA in the SPY-1 was responsible for the highest concentration of GABA in the SPY-1. Also, the levels of isoflavone glycoside (genistin, glycitin, and daidzin) decreased, while the total phenolic and isoflavone aglycone (genistein, glycitein, and daidzein) contents increased throughout fermentation for $72 \mathrm{~h}$; however, the glycitein content slightly increased (Table 1).

Liao et al. [21] reported that the increasing commercial demand for GABA has led to diverse foods containing both biologically and chemically produced GABA. For example, GA- and GABA-enriched green tea and the germination of unpolished rice are produced by an anaerobic treatment, and in rice germ, it is produced by soaking in water via a high-pressure treatment. Upon germination in brown rice, in tempeh-like fermented soybean and in black raspberry juice, GABA enrichment is achieved by fermentation by L. brevis $[11,21,22]$. The highest concentration of GA in the SPM-1 was responsible for the highest concentration of GABA in the SPY-1. Additionally, Koo et al. [12] recently reported that the total phenolic contents (TPCs) were higher in soybean sprouts than in soybean seeds, corresponding to the higher antioxidant activity that appeared. Several researchers previously reported that the total phenolic and isoflavone aglycone contents were enhanced during the lactic acid fermentation of soymilk by Lactobacillus plantarum P1201 [18].

\section{Change in pH, acidity, and enzyme activities during the fermentation of SPY-1}

Changes in the $\mathrm{pH}$, acidity, and glutamate decarboxylase and $\beta$-glucosidase activities in during the fermentation SPY-1 with L. brevis are shown in Table 2. As shown, the $\mathrm{pH}$ decreased during fermentation from 6.82 to 5.03 after $72 \mathrm{~h}$, whereas the acidity increased $0.07-0.54 \%$ after $72 \mathrm{~h}$ of fermentation. The viable cell numbers gradually increased from $12 \mathrm{~h}(9.47 \mathrm{cfu} / \mathrm{mL})$ to $36 \mathrm{~h}(13.39 \mathrm{cfu} / \mathrm{mL})$, whereas they negligibly decreased from $48 \mathrm{~h}(12.48 \mathrm{cfu} /$ $\mathrm{mL})$ to $72 \mathrm{~h}(11.47 \mathrm{cfu} / \mathrm{mL})$ of fermentation. The glutamate decarboxylase activity was the highest $(4.87 \mathrm{unit} / \mathrm{mL}$ and $36 \mathrm{~h}$ ), whereas it slightly decreased during fermentation times of $48 \mathrm{~h}(4.26 \mathrm{unit} / \mathrm{mL}), 60 \mathrm{~h}(3.95 \mathrm{unit} / \mathrm{mL})$, and $70 \mathrm{~h}(3.85$ unit $/ \mathrm{mL})$. The $\beta$-glucosidase activity rapidly increased during the first $12 \mathrm{~h}$ of SPY-1 fermentation, reaching $1.78 \mathrm{unit} / \mathrm{mL}$ of SPY-1. Then, it increased gradually with a longer fermentation time until $48 \mathrm{~h}$ (2.76 unit/ $\mathrm{mL}$ ) and thereafter slightly decreased (Table 2).

Table 2 Changes in the $\mathrm{pH}$, acidity, viable cell numbers, and enzyme activity during the fermentation of SPY-1 with L. brevis

\begin{tabular}{|c|c|c|c|c|c|}
\hline \multirow{2}{*}{$\begin{array}{l}\text { Fermentation } \\
\text { time }(\mathrm{h})\end{array}$} & \multicolumn{5}{|l|}{ Contents $^{\mathrm{a}}$} \\
\hline & $\mathrm{pH}$ & $\begin{array}{l}\text { Acidity }(\%, \text { as } \\
\text { lactic acid) }\end{array}$ & $\begin{array}{l}\text { Viable cell numbers }(\log \\
\mathrm{cfu} / \mathrm{mL})\end{array}$ & $\begin{array}{l}\text { Glutamate decarboxylase } \\
\text { activity (unit } / \mathrm{mL} \text { ) }\end{array}$ & $\begin{array}{l}\beta \text {-glucosidase activity } \\
\text { (unit } / \mathrm{mL} \text { ) }\end{array}$ \\
\hline 0 & $6.82 \pm 0.41^{\mathrm{a}}$ & $0.07 \pm 0.00^{\mathrm{b}}$ & $7.06 \pm 0.60^{\mathrm{b}}$ & $0.14 \pm 0.00^{\mathrm{d}}$ & $0.12 \pm 0.00^{\mathrm{c}}$ \\
\hline 12 & $5.59 \pm 0.34^{b}$ & $0.40 \pm 0.02^{\mathrm{a}}$ & $9.47 \pm 0.63^{\mathrm{b}}$ & $0.88 \pm 0.03^{\mathrm{d}}$ & $1.78 \pm 0.02^{\mathrm{b}}$ \\
\hline 24 & $5.39 \pm 0.32^{\mathrm{b}}$ & $0.43 \pm 0.03^{\mathrm{a}}$ & $10.68 \pm 0.64^{\mathrm{a}}$ & $2.94 \pm 0.04^{\mathrm{c}}$ & $2.04 \pm 0.03^{\mathrm{a}}$ \\
\hline 36 & $5.37 \pm 0.32^{\mathrm{b}}$ & $0.44 \pm 0.03^{\mathrm{a}}$ & $13.39 \pm 0.80^{\mathrm{a}}$ & $4.87 \pm 0.06^{\mathrm{a}}$ & $2.37 \pm 0.03^{\mathrm{a}}$ \\
\hline 48 & $5.26 \pm 0.32^{\mathrm{b}}$ & $0.47 \pm 0.03^{\mathrm{a}}$ & $12.48 \pm 0.75^{\mathrm{a}}$ & $4.26 \pm 0.05^{\mathrm{a}}$ & $2.76 \pm 0.05^{\mathrm{a}}$ \\
\hline 60 & $5.18 \pm 0.31^{\mathrm{b}}$ & $0.50 \pm 0.03^{\mathrm{a}}$ & $11.52 \pm 0.69^{\mathrm{a}}$ & $3.95 \pm 0.04^{\mathrm{b}}$ & $2.72 \pm 0.04^{\mathrm{a}}$ \\
\hline 72 & $5.03 \pm 0.30^{\mathrm{b}}$ & $0.54 \pm 0.03^{\mathrm{a}}$ & $11.47 \pm 0.69^{\mathrm{a}}$ & $3.85 \pm 0.04^{\mathrm{b}}$ & $2.67 \pm 0.05^{\mathrm{a}}$ \\
\hline
\end{tabular}

${ }^{a}$ All values are presented as the mean \pm SD of triplicate determination. All values within a column with different superscript letters are significantly different from each other at $p<0.05$ by Duncan's multiple range tests 


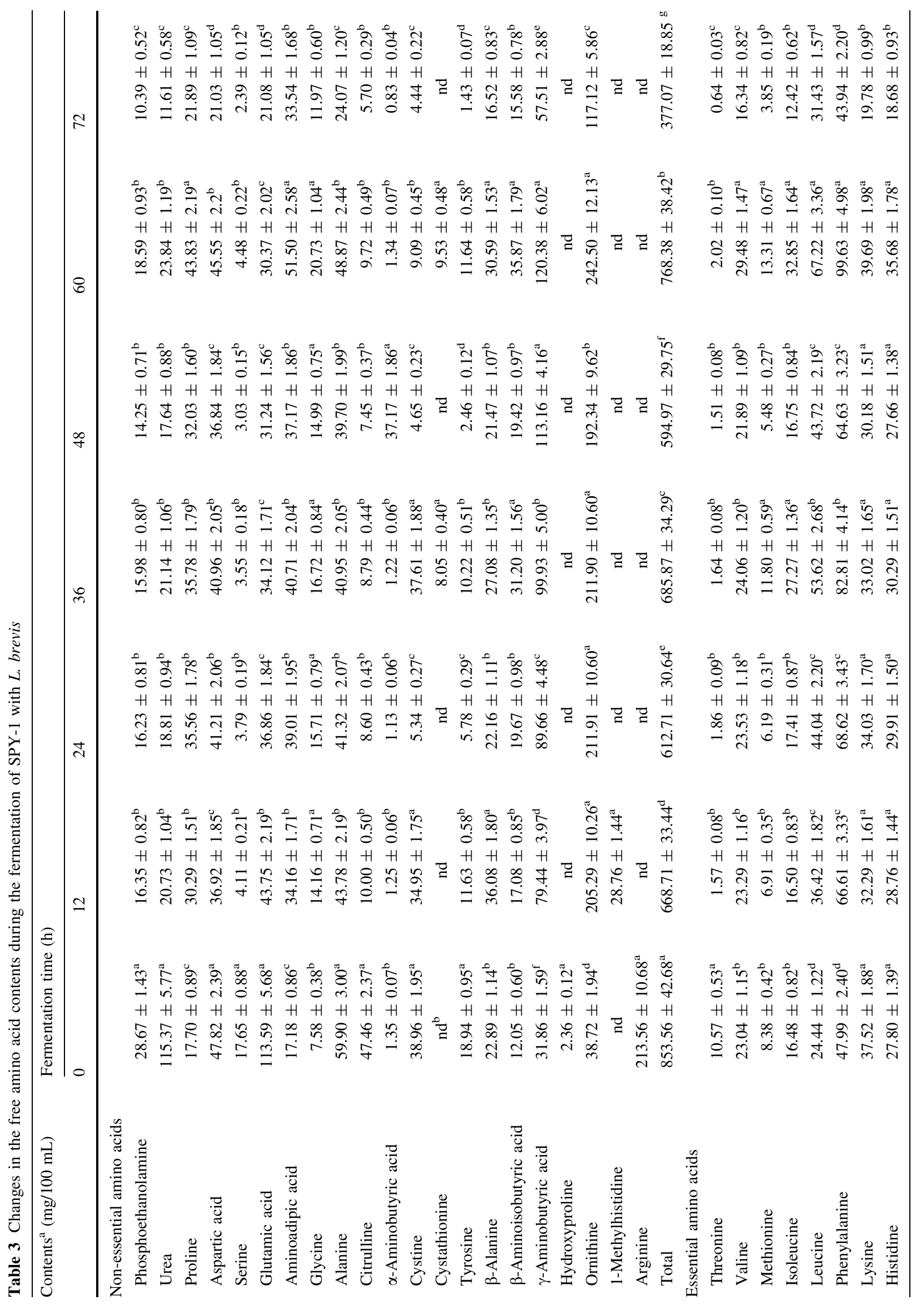




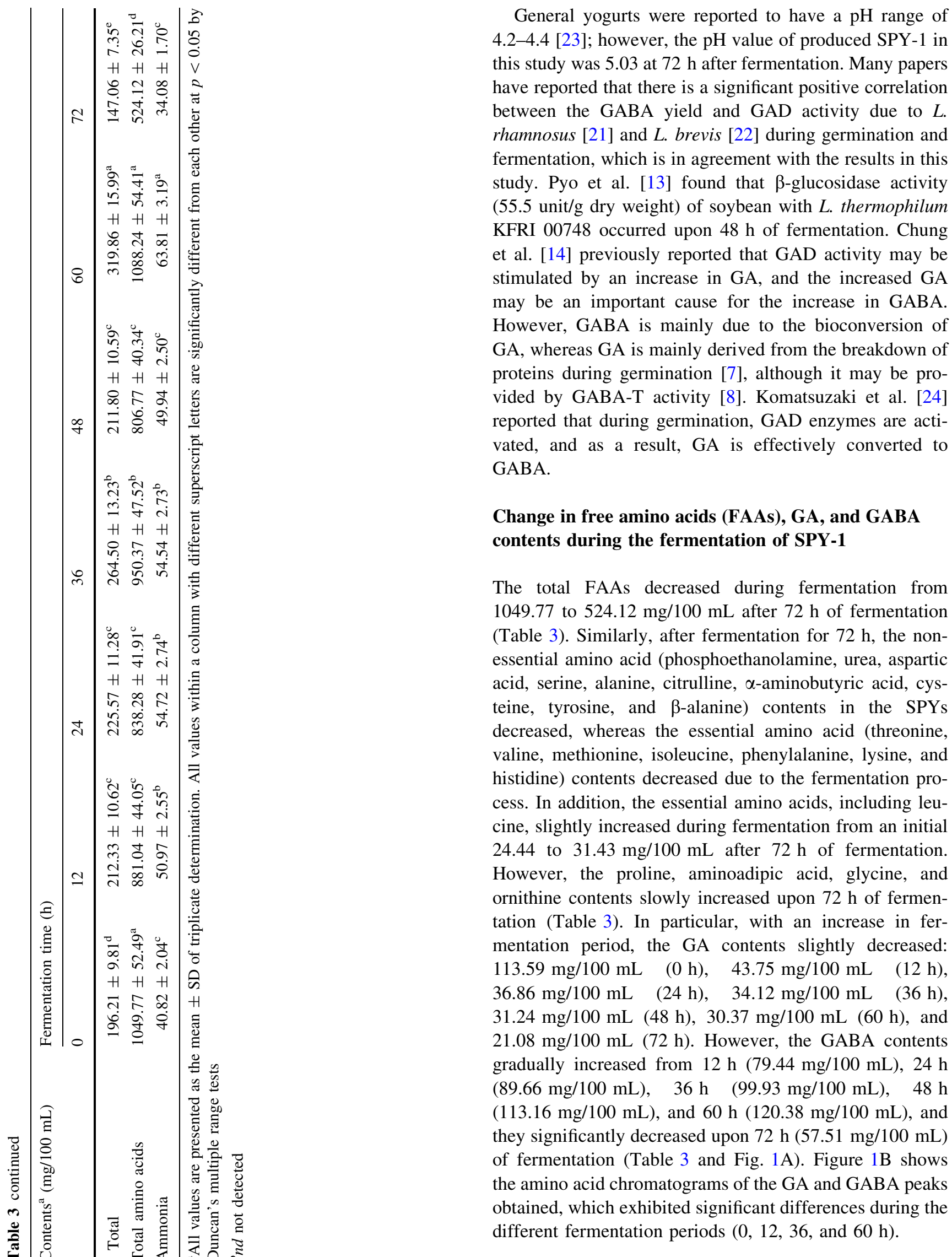




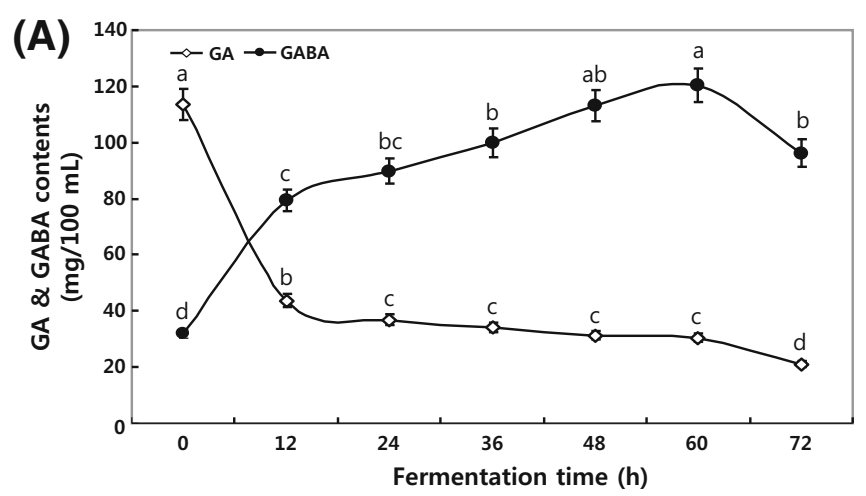

(B)
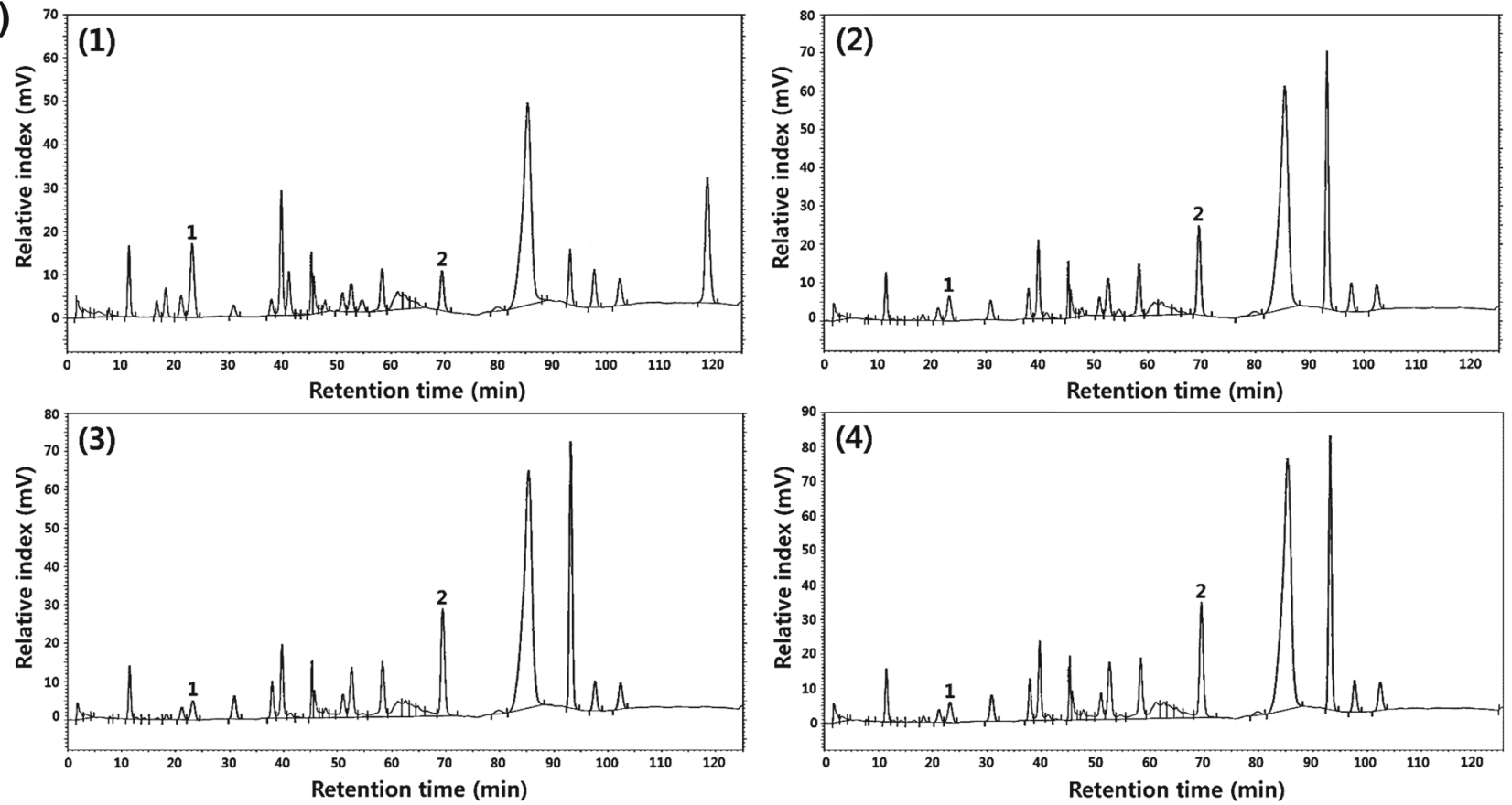

Fig. 1 Change in the glutamic acid (GA) and $\gamma$-aminobutyric acid (GABA) contents during the fermentation of SPY-1 with L. brevis. (A) Graph of GA and GABA profiles and (B) typical chromatogram of GA and GABA. B1; fermentation period of $0 \mathrm{~h}, \mathrm{~B} 2$; fermentation period of $12 \mathrm{~h}, \mathrm{~B} 3$; fermentation period of $36 \mathrm{~h}$, and B4; fermentation

period of $60 \mathrm{~h}$. 1; GA and 2; GABA. All values are presented as the mean $\pm \mathrm{SD}$ of triplicate determination. All values within a column with different superscript letters are significantly different from each other at $p<0.05$ by Duncan's multiple range tests

The GA metabolic rate results in GABA creation, and serine, alanine, valine, and leucine have activities as vasodilators, which lower blood pressure and fatigue recovery [25]. It has been reported that microbial fermentation can produce GABA [26]. GAD is required for organisms to produce GABA because it can catalyze the decarboxylase of glutamate to $\mathrm{GABA}$ and $\mathrm{CO}_{2}$. Microbial GAD is the most extensively studied and has been purified and produced from L. brevis [25] and L. paracasei [27]. Liao et al. [21] reported that the GABA contents were 201.2 and $68.2 \mathrm{mg} / 100 \mathrm{~g}$ upon cold shock and fermentation, respectively, by lactic acid bacteria with adzuki bean. Lee et al. [28] reported that the GA yield was $2789 \mathrm{mg} / \mathrm{L}$ before fermentation and significantly decreased during fermentation, and the GABA yield significantly increased in sea tangle during fermentation with $L$. brevis $\mathrm{BJ} 20$ after 
5 days of fermentation. After fermentation, most of the GA was converted to GABA, and some contents of free amino acids, such as aspartic acid, serine, and threonine, decreased during fermentation, which is in agreement with our results [28].

\section{Changes in the total phenolic and isoflavone contents during the fermentation of SPY-1}

The TPCs increased from 3.61 to $5.89 \mathrm{mg} / \mathrm{g}$ during the fermentation of SPY-1 with L. brevis (Fig. 2). As shown in Fig. 3, the content of isoflavone glycoside and malonylglycoside decreased, whereas the isoflavone aglycones (daidzein, glycitein, and genistein) increased. In the case of SPY, the isoflavone aglycone contents increased throughout fermentation to approximately 24.5 -fold relative to the starting amounts after $72 \mathrm{~h}$ of fermentation (3.33-81.68\%). However, the glycoside contents decreased from 87.51 to $8.09 \%$ at $72 \mathrm{~h}$ (Fig. 3A). Figure 3B shows the HPLC chromatograms of the isoflavone peaks obtained, showing significant differences during the different fermentation periods $(0,12,36$ and $60 \mathrm{~h})$. Importantly, with an increase in fermentation period, the total isoflavone contents slightly decreased upon fermentation from $0 \mathrm{~h}(898.12 \mu \mathrm{g} / \mathrm{g})$ to $72 \mathrm{~h}(428.85 \mu \mathrm{g} / \mathrm{g})$. In particular, daidzin of the glycoside contents decreased from 305.24 to $22.06 \mu \mathrm{g} / \mathrm{g}$, and the corresponding daidzein of the aglycone contents increased to $179.93 \mu \mathrm{g} / \mathrm{g}$ at $72 \mathrm{~h}$ of fermentation (Table 2).

Germination and fermentation can increase the total phenolic and isoflavone aglycone contents and change the isoflavone compositions of soybean. Fermented processing disintegrates the cell wells and cell membranes and releases soluble phenolic contents from the insoluble ester bonds by acid and estrolytic enzymes [18]. Paucar-Menacho et al. [29] reported that the composition of isoflavone profiles significantly changed after fermentation and germination effects on the soybean cultivars and the process of germination. Ewe et al. [4] reported that biotin-supplemented fermented soymilk had isoflavone aglycone contents that increased from 22.9 to $131.5 \%$ due to fermentation. This result enhanced the bioconversion of glycosides to aglycones due to the $\beta$-glycosidase activity during fermentation by L. brevis in soymilk [4]. In addition, Hwang et al. [18] reported an increase in TPCs and isoflavone aglycones, such as daidzein and genistein, in SPM as the fermentation time increased. Additionally, Lin and Lai [30] reported that the ratio of isoflavone aglycones and total isoflavones improved by germination in black soybeans. Meanwhile, Devi et al. [31] reported that germinated soybean had the highest isoflavone content among soybean products, such as soy milk, soy sauce, soy meals and soy flour and soy seeds. Thus, the bioconversion rates of glycosides to aglycones in SPY are different according to the soybean cultivar and germination conditions (Table 4).

\section{Change in the radical scavenging activities during the fermentation of SPY-1}

In this study, the ascorbic acid (a positive control) showed DPPH, ABTS, and hydroxyl radical scavenging activities of $80.22,98.46$, and $78.22 \%$, respectively, at 0.5 or $0.25 \mathrm{mg} / \mathrm{mL}$. Similarly, the SPY-1 exhibited stronger radical scavenging activities upon fermentation periods of $72 \mathrm{~h}$ (Fig. 4). The activity of the DPPH radical increased steadily from $48.97 \%$ at $0 \mathrm{~h}$ of fermentation to $69.65 \%$ upon $72 \mathrm{~h}$ of fermentation (Fig. 4A). The ABTS radical activities upon fermentation for 0 and $72 \mathrm{~h}$ significantly increased by 69.66 and 97.64\%, respectively (Fig. 4B). Similarly, the hydroxyl radical scavenging activity increased from 36.22 to $70.90 \%$ upon $72 \mathrm{~h}$ (Fig. 4C).

The total phenolic, isoflavone, anthocyanin, and tocopherol contents represent important biological activities, such as antioxidant activity, a capillary protective effect, and human health benefits, in various stages of tumors [32]. The increased free radical scavenging activity of fermented soymilk observed in the present study is consistent with previous reports [18, 33]. Chun et al. [23] reported a significant correlation between the antioxidant activity of isoflavone aglycone and phenolic contents in soymilk. Therefore, it is expected that the high antioxidant activity of SPY from high-protein soybean cultivars may be related

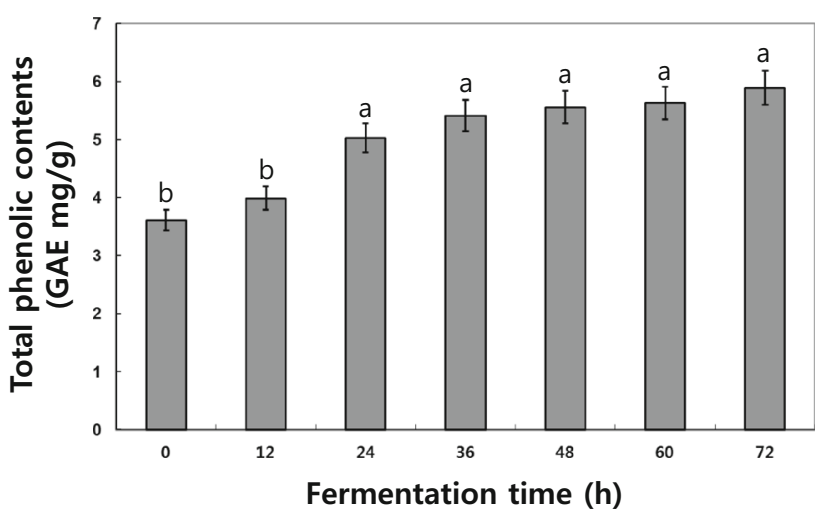

Fig. 2 Change in the total phenolic contents during the fermentation of SPY-1 with L. brevis. All values are means from three independent experiments. All values are presented as the mean \pm SD of triplicate determination. All values within a column with different superscript letters are significantly different from each other at $p<0.05$ by Duncan's multiple range tests 


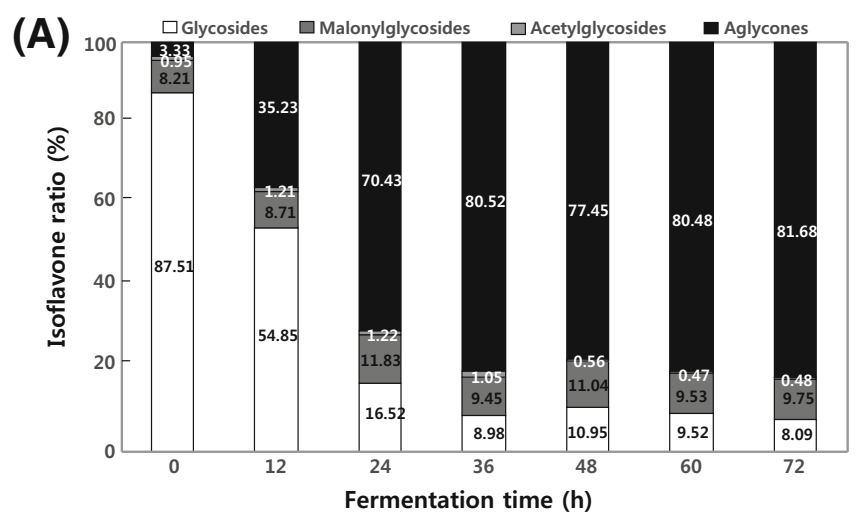

(B)
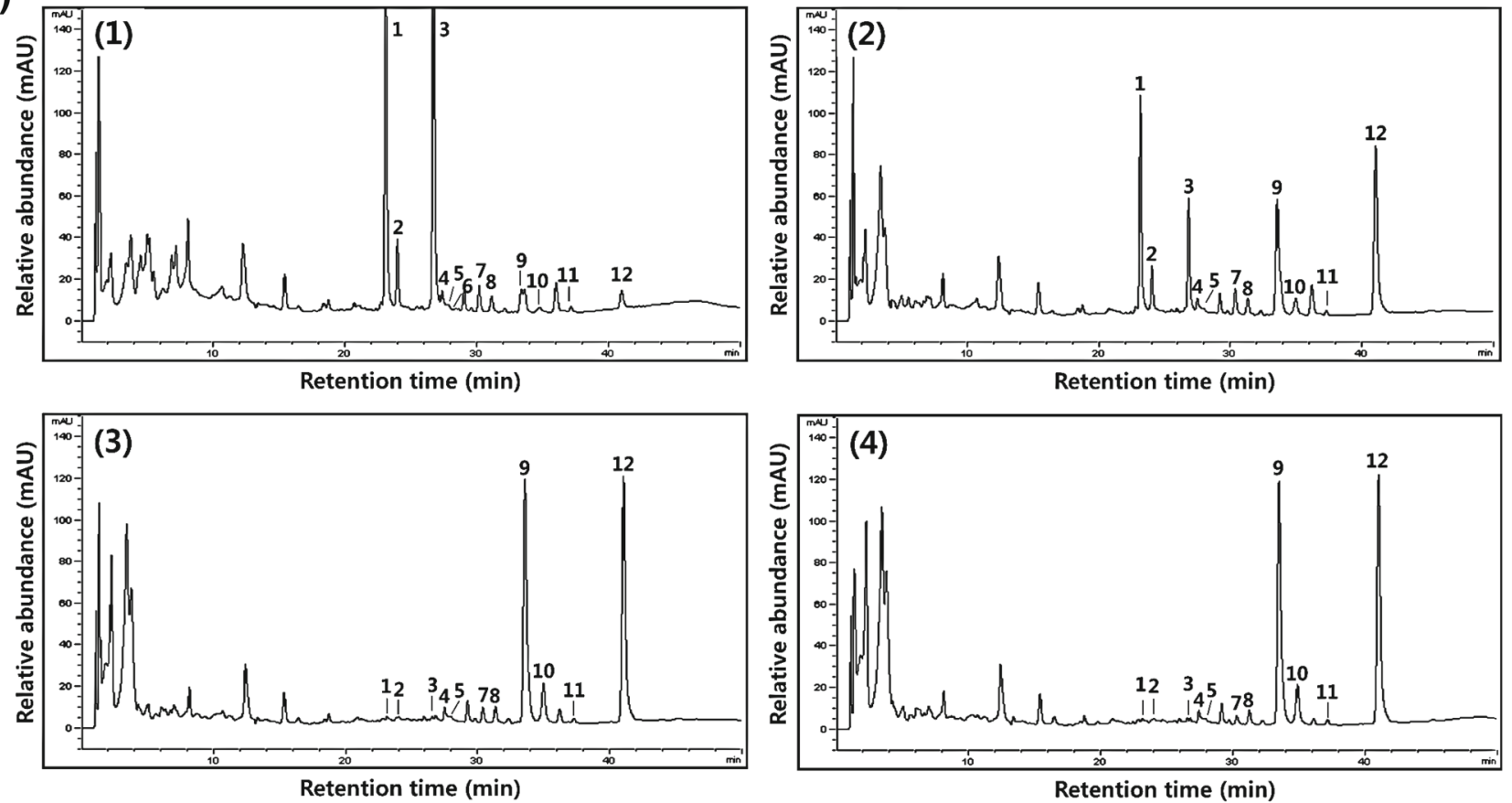

Fig. 3 Change in the isoflavone contents during the fermentation of SPY-1 with L. brevis. (A) Graph of isoflavone ratio and (B) typical chromatogram of isoflavone. B1; fermentation period of $0 \mathrm{~h}, \mathrm{~B} 2$; fermentation period of $12 \mathrm{~h}, \mathrm{~B} 3$; fermentation period of $36 \mathrm{~h}$, and B4;

to the significant isoflavone aglycone contents achieved during fermentation.

In conclusion, the contents of GABA, total phenolic, and isoflavone aglycones and radical (DPPH, ABTS, and hydroxyl) scavenging activities were increased, while the isoflavone glycoside and malonylglycoside contents decreased during the SPY due to sprouting of soybean $(1 \mathrm{~cm})$ fermentation with L. brevis. The level of GABA

fermentation period of $60 \mathrm{~h} .1$; daidzin, 2; glycitin, 3; genistin, 4; malonyldaidzin, 5; malonylglycitin, 6; acetyldaidzin, 7; acetylglycitin, 8; malonylgenistin, 9; daidzein, 10; glycitein, 11; acetyl genistein, and 12; genistein

$(120.38 \mathrm{mg} / 100 \mathrm{~mL})$ was the highest at $60 \mathrm{~h}$. On the other hand, the contents of daidzein $(179.93 \mu \mathrm{g} / \mathrm{g})$, glycitein $(44.10 \mu \mathrm{g} / \mathrm{g})$, and genistein $(126.24 \mu \mathrm{g} / \mathrm{g})$ were the highest after the end fermentation time $(72 \mathrm{~h})$, respectively. These results suggest that SPY can be used for the production of HPS with the high GABA, total phenolic, and isoflavone aglycone contents, which can be used as a natural component of functional foods. 


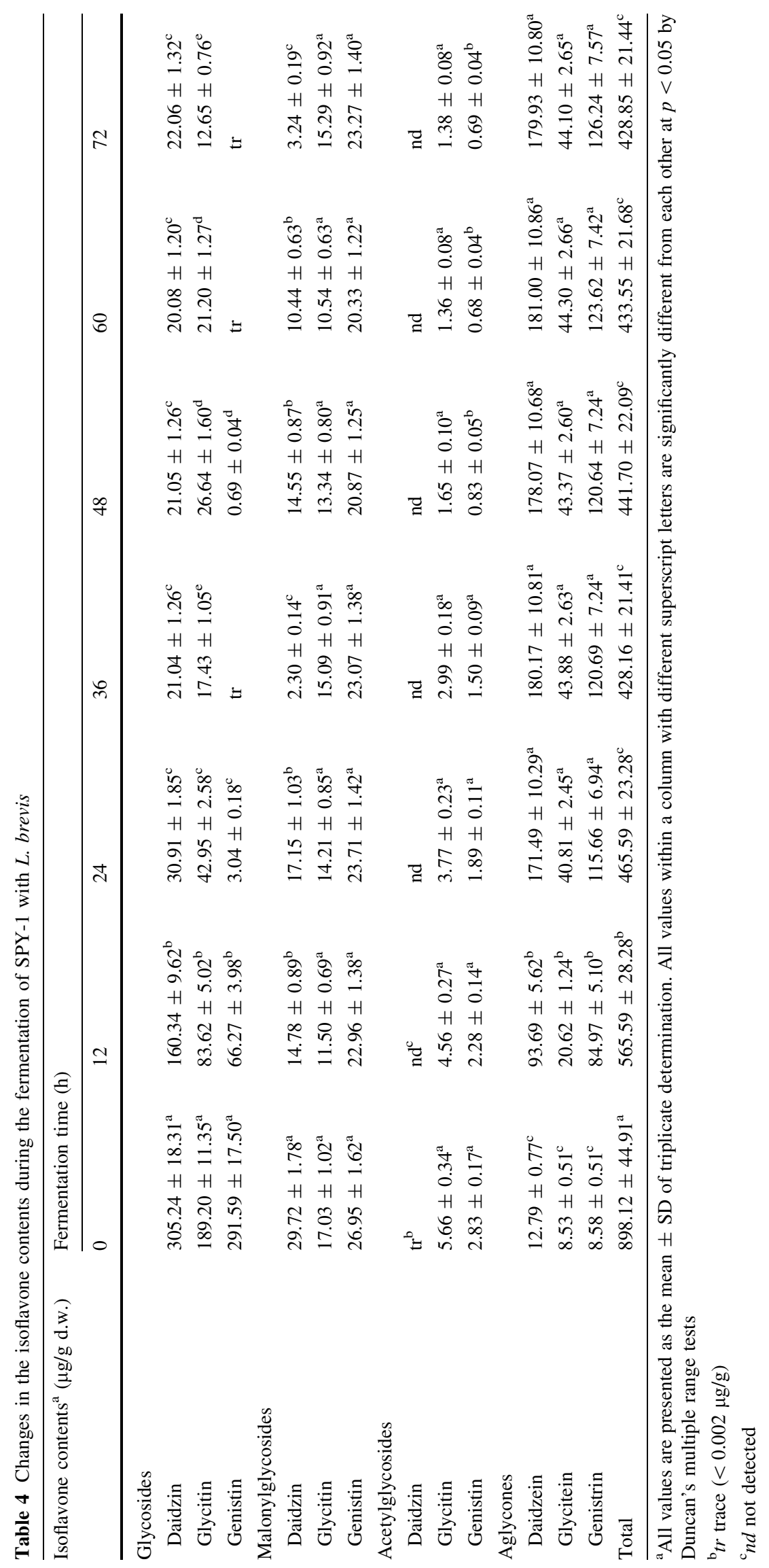



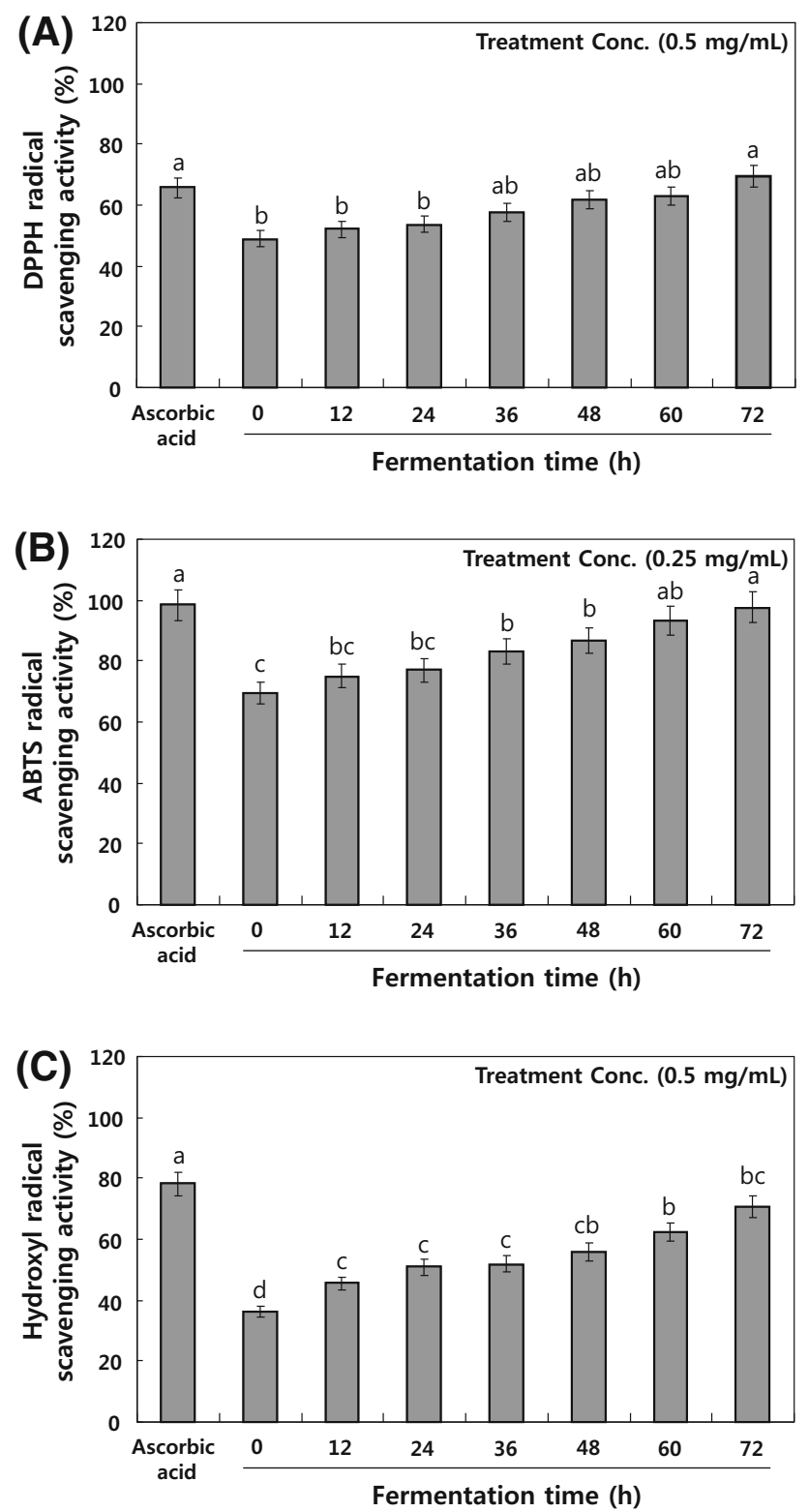

Fig. 4 Change in the antioxidant activity during the fermentation of soy powder yogurt (SPY) with L. brevis. (A) DPPH, (B) ABTS, and (C) hydroxyl radical scavenging activity. All values are means from three independent experiments. All values are presented as the mean $\pm \mathrm{SD}$ of triplicate determination. All values within a column with different superscript letters are significantly different from each other at $p<0.05$ by Duncan's multiple range tests

Acknowledgment This research was supported by the Basic Science Research Program through the National Research Foundation of Korea (NRF) funded by the Ministry of Education, Science and Technology (Grant number 2016R1D1A1B01009898) and by Technology Commercialization Support Program (Grant number 315032-4), Ministry of Agriculture, Food and Rural Affairs, Republic of Korea.

\section{References}

1. Huang X, Cai W, Xu B (2014) Kinetic changes of nutrients and antioxidant capacities of germinated soybean (Glycine max. L) and mung bean (Vigna radiata $\mathrm{L}$.) with germination time. Food Chem 143:268-276

2. Lee JH, Hwang SR, Lee YH, Kim K, Cho KM, Lee YB (2015) Changes occurring in compositions and antioxidant properties of healthy soybean seeds [Glycine $\max (\mathrm{L}$.) Merr.] and soybean seeds diseased by Phomopsis longicolla and Cercospora kikuchii fungal pathogens. Food Chem 185:205-211

3. Lee JH, Lee BW, Kim B, Kim HT, Ko JM, Baek IY, Seo WT, Kang YM, Cho KM (2013) Changes in phenolic compounds (isoflavones and phenolic acids) and antioxidant properties in high-protein soybean (Glycine max L., cv. Saedanbaek) for different roasting conditions. J Korean Soc Appl Biol Chem 56:605-612

4. Ewe JA, Wan-Nadizh WA, Abdul KA, Liong MT (2012) Bioconversion of isoflavones and the probiotic properties of the electroporated parent and subsequent three subcultures of $\mathrm{Lac}$ tobacillus fermentum BT 8219 in biotin-soymilk. J Microbiol Biotechnol 22:947-959

5. Shi H, Nam PK, Ma Y (2010) Comprehensive profiling of isoflavones, phytosterols, minerals, crude protein, lipid, and sugar during soybean (Glycine max) germination. J Agric Food Chem 58:4970-4976

6. Wang F, Wang H, Wang D, Fang F, Lai J, Wu T, Tsao R (2015) Isoflavone, $\gamma$-aminobutyric acid contents and antioxidant activities are significantly increased during germination of three Chinese soybean cultivars. J Funct Foods 14:596-604

7. Xu JG, Hu QP (2014) Changes in $\gamma$-aminobutyric acid content and related enzyme activities in Jindou 25 soybean (Glycine max L.) seeds during germination. LWT Food Sci Technol 55:341-346

8. Bouche N, Fromm H (2004) GABA in plants: just a metabolite? Trends Plant Sci 9:111-115

9. Thuwapanichayanan R, Yoosabai U, Jaisut D, Soponronnarit S, Prachayawarakorn S (2015) Enhancement of $\gamma$-aminobutyric acid in germinated paddy by soaking in combination with anaerobic and fluidized bed heat treatment. Food Bioprod Process 95:55-62

10. Guo Y, Chen H, Song Y, Gu Z (2011) Effects of soaking and aeration treatment on $\gamma$-aminobutyric acid accumulation in germinated soybean (Glycine max L.). Eur Food Res Technol 232:787-795

11. Kim NY, Ji GE (2014) Characterization of soybean fermented by aflatoxin non-producing Aspergillus oryzae and $\gamma$-aminobutyric acid producing Lactobacillus brevis. J Korean Soc Appl Biol Chem 57:703-708

12. Koo SC, Kim SG, Bae DW, Kim HY, Kim HT, Lee YH, Kang BK, Baek SB, Baek IY, Yun HT, Choi MS (2015) Biochemical and proteomic analysis of soybean sprouts at different germination temperatures. J Korean Soc Appl Biol Chem 58:397-407

13. Pyo YH, Lee TC, Lee YC (2005) Effect of lactic acid fermentation on enrichment of antioxidant properties and bioactive isoflavones in soybean. J Food Sci 70:215-220

14. Chung HJ, Jang SH, Cho HY, Lim ST (2009) Effects of steeping and anaerobic treatment on GABA ( $\gamma$-aminobutyric acid) content in germinated waxy hull-less barley. LWT Food Sci Technol 42:1712-1716

15. Shi X, Chang C, Ma S, Cheng Y, Zhang J, Gao Q (2017) Efficient bioconversion of L-glutamate to $\gamma$-aminobutyric acid by Lactobacillus brevis resting cells. J Ind Microbiol Biotechnol 44:697-704 
16. Herraiz T, Galisteo J (2015) Hydroxyl radical reactions and the radical scavenging activity of $\beta$-carboline alkaloids. Food Chem 172:640-649

17. Chang C, Zhang J, Ma S, Wang L, Wang D, Zhang J, Gao Q (2017) Purification and characterization of glutamate decarboxylase from Enterococcus raffinosus TCCC11660. J Ind Microbio Biotechnol 44:817-824

18. Hwang CE, An MJ, Lee HY, Lee BW, Kim HT, Ko JM, Baek IY, Seo WT, Cho KM (2014) Potential probiotic Lactobacillus plantarum P1201 to produce soy-yogurt with enhanced antioxidant activity. Korean J Food Sci Technol 46:556-565

19. Yu K, Hu S, Huang J, Mei LH (2011) A high-throughput colorimetric assay to measure the activity of glutamate decarboxylase. Enzyme Microb Technol 49:272-276

20. Cho KM, Lee JH, Yun HD, Ahn BY, Kim H, Seo WT (2011) Changes of phytochemical constituents (isoflavones, flavonols and phenolic acids) during cheonggukjang soybeans fermentation using potential probiotics Bacillus subtilis CS90. J Food Compos Anal 24:402-410

21. Liao WC, Wang CY, Shyu YT, Yu RC, Ho KC (2013) Influence of preprocessing methods and fermentation of adzuki beans on $\gamma$ aminobutyric acid (GABA) accumulation by lactic acid bacteria. J Funct Foods 5:1108-1115

22. Kim JY, Lee MY, Ji GE, Lee YS, Hwang KT (2009) Production of $\gamma$-aminobutyric acid in black raspberry juice during fermentation by Lactobacillus brevis GABA 100. Int J Food Microbiol 130:12-16

23. Chun JY, Kim JS, Kim JH (2008) Enrichment of isoflavone aglycones in soymilk by fermentation with single and mixed cultures of Streptococcus infantarius 12 and Weissella sp. 4. Food Chem 15:278-284

24. Komatsuzaki N, Tsukahara K, Toyoshima H, Suzuki T, Shimizu N, Kimura T (2007) Effect of soaking and gaseous treatment on GABA content in germinated brown rice. J Food Eng 78:556-560
25. Chiu TH, Tsai SJ, Wu TY, Fu SC, Hwang YT (2013) Improvement in antioxidant activity angiotensin-converting enzyme inhibitory activity and in vitro cellular properties of fermented pepino milk by Lactobacillus strains containing the glutamate decarboxylase gene. J Sci Food Agric 93:859-866

26. Shelp BJ, Bown AW, McLean MD (1999) Metabolism and functions of gamma-aminobutyric acid. Trends Plant Sci $4: 446-452$

27. Komatsuzaki N, Nakamura T, Shima J (2008) Characterization of glutamate decarboxylase from a high $\gamma$-aminobutyric acid (GABA)-producer, Lactobacillus paracasei. Biosci Biotechnol Biochem 72:278-285

28. Lee BJ, Kim JS, Kang YM, Lim JH, Kim YM, Lee MS, Jeong $\mathrm{MH}$, Ahn CB, Je JY (2010) Antioxidant activity and $\gamma$ aminobutyric acid (GABA) content in sea tangle fermented by Lactobacillus brevis BJ20 isolated from traditional fermented foods. Food Chem 122:271-276

29. Paucar-Menacho LMA, Berhow M, Gontijo Mandarino JM, Chang YK, de Mejia G (2010) Effect of time and temperature on bioactive compounds in germinated Brazilian soybean cultivars BRS 258. Food Res Int 43:1856-1865

30. Lin PY, Lai HM (2006) Bioactive compounds in legumes and their germinated products. J Agric Food Chem 54:3807-3814

31. Devi MKA, Gondi M, Sakthivelu G, Giridhar P, Rajasekaran T, Ravishankar GA (2009) Functional attributes of soybean seeds and products, with reference to isoflavone content and antioxidant activity. Food Chem 114:771-776

32. Yang SC, Chen TI, Li KY, Tsai TC (2007) Change in phenolic compound content, reductive capacity and ACE inhibitory activity in Noni juice during traditional fermentation. J Food Drug Anal 15:290-298

33. Yang JH, Mau JL, Ko PT, Huang LC (2000) Antioxidant properties of fermented soybean broth. Food Chem 71:249-254 